\title{
LETTER: A CARTA/LETRA E O JOGO DA CORRESPONDÊNCIA
}

\author{
Joacy Ghizzi Neto* \\ Universidade Federal de Santa Catarina
}

Resumo: O presente ensaio tem como ponto de partida a leitura do conto "A carta roubada" de Edgar Alan Poe e suas análises elaboradas por Jacques Lacan em "O Seminário sobre A carta roubada" (Escritos, 1998) e por Jacques Derrida em "O carteiro da verdade" (O cartãopostal, 2007), além da leitura de Nancy e Labarthe em $O$ título da letra (1991) e ainda Rene Major em Lacan com Derrida (2002). O texto tem como aposta a potência do significante letter/lettre que significa tanto "carta" quando "letra", daí sua potência, da carta/letra, como possível literatura. O trabalho ainda conta com leituras, acerca da epistolografia, de Josefina Ludmer, Emile Cioran, Juan José Saer, Liliana Heer e Silviano Santiago. O trabalho aborda também a leitura de Michel Foucault em "A escrita de si" (O que é um autor?, 1992) que pensará a correspondência como uma forma de escrita de si, apesar de destinada ao outro. A partir disto, o presente ensaio tem como objetivo principal pensar o procedimento da correspondência entre artistas/poetas como um jogo de posições ambivalentes, e não como uma troca estática de mensagens entre remetente e destinatário.

Palavras-chave: Cartas. Correspondência. Epistolografia. Derrida. Lacan.

No conto "A carta roubada" (The purloined letter) de Edgar Allan Poe, a polícia parisiense encontra-se em situação constrangedora. Ao não conseguir resolver um caso por conta própria, recorre aos serviços do detetive amador Dupin. O comissário da polícia G. assume estar diante de um caso muito simples, porém não consegue resolvê-lo. Precisa-se recuperar um objeto, sabendo inclusive quem lhe detém a posse no momento - o ministro D. Porém, ainda assim, não conseguem encontrá-lo nos aposentos do ministro, mesmo depois de diversas inspeções noturnas na ausência de D. A forma como a narrativa apresenta tal objeto, em sequência, é a seguinte: “certain document; document; paper; document; document”, somente após estas cinco aparições que G. afirmará o seguinte: "The document in question - a letter, to be frank [...]" (POE, 2009, p.123). Mesmo após a necessidade de franqueza para que G. assumisse a identidade do objeto em questão, mantém-se uma não uniformidade para

\footnotetext{
* Bacharel em Letras-Português (UFSC), atualmente é bolsista CNPq (nível Mestrado) no Programa de PósGraduação em Literatura da UFSC, no qual desenvolve a dissertação "Cartas de Paulo Leminski: Sinais de Vida".
} 
referir-se ao objeto na narrativa (ou sujeito $d a$ narrativa, como afirmará Lacan.) Em continuidade à sequência até o fim do conto: "paper; letter; letter; letter; document; paper; thing; letter; letter; letter; purloined letter; document; letter; solitary letter; letter; document; paper; letter; letter; letter.”.

Após o próprio título, mantém-se um suspense, ou mantém-se a carta em suspenso, demorando a assumir-lhe a identidade de carta e mesmo assim tal identidade oscila. Mas essa característica de ambiguidade é acentuada pelo próprio significante letter, que em inglês significa tanto carta quanto letra, da mesma forma que o lettre em francês. Ou seja, o fator de indecidibilidade na narrativa está atrelado à própria materialidade do significante em jogo. Jacques Lacan toma o conto de Poe como objeto de uma conferência para analistas: "O seminário sobre "A carta roubada"” é proferido em 1955, escrito em 56, publicado em 57 e em 66 ganhará espaço emblemático de abertura na reunião Escritos do psicanalista francês. Lacan assumira uma perspectiva de leitura que potencialize a singularidade carta/letra, a despeito do seu desvio de percurso, mas justamente devido a ele, como "verdadeiro sujeito do conto: é por poder sofrer um desvio que ela tem um trajeto que lhe é próprio." e ainda Lacan:

\begin{abstract}
Assim nos vemos confirmados, em nosso desvio, pelo próprio objeto que a ele nos leva: pois é justamente a carta desviada que nos ocupa, aquela cujo trajeto foi alongado [prolongé], ou, para recorrer ao vocabulário postal, la lettre em soufrrance, a carta não retirada. (LACAN, 1998, p. 33)
\end{abstract}

Devido a posse assumida da carta/letra por D., a letter que então era destinada a Rainha passa a ficar em mãos do ministro. Ou seja, é através de uma intervenção que o trajeto da carta/letra é desviado. Entretanto, este desvio do trajeto não implica que o significante mesmo sofra alteração:

Pois o significante é unidade por ser único, não sendo, por natureza, senão símbolo de uma ausência. E é por isso que não podemos dizer da carta/letra roubada que, à semelhança de outros objetos, ela deve estar ou não em algum lugar, mas sim que, diferentemente deles, ela estará $e$ não estará onde estiver, onde quer que vá. (LACAN, 1998, p. 27)

Ou seja, a carta/letra não possui um lugar fixo e está em um jogo de posses. Talvez o questionamento central de Lacan (1998, p. 30) que permitirá uma leitura acerca da correspondência é o seguinte: "Para que haja carta roubada, diremos conosco, a quem pertence uma carta/letra?". Esta pergunta abre-se para uma série de questões, inclusive a da própria propriedade de uma carta, dando lugar a vulnerável detenção: "Então, a carta/letra sobre a qual quem a enviou ainda conserva direitos não pertenceria plenamente àquele a quem 
se dirige? Ou será que este último nunca foi seu verdadeiro destinatário?” (LACAN, 1998, p. $30)$.

Apesar do desvio, é através dos serviços do investigador - e poeta - Dupin, que a carta cumprirá seu trajeto até o destino, de volta para a Rainha. Interessante notar, então, que a despeito do percurso ser interrompido, ele se cumpre, como atesta Derrida, de forma circular. No texto Le facteur de la vérite ("O carteiro da verdade"), Derrida, ao ler o Seminário sobre "A carta roubada", detectará em Lacan a "preeminência do significante sobre o sujeito" e "a supremacia do significante do sujeito". E assim, Derrida também questionará a estabilidade do remetente/destinatário:

Existe detenção, mas não propriedade da carta. Esta última nunca será possuída, nem por seu remetente nem por seu destinatário. [...] Logo, esta carta, aparentemente, não tem proprietário. Ela não é, aparentemente, propriedade de ninguém. Ela não tem sentido próprio, nenhum conteúdo próprio que importe, em aparência, a seu trajeto. Ela é, portanto, estruturalmente voadora e roubada. (DERRIDA, 2007, p. 468)

Sendo assim, não há um sujeito que controla o sentido da carta/letra. Nem seu sentido como mensagem ou conteúdo, nem seu sentido como direção: "Essa história é decerto a de uma carta, do roubo e do deslocamento de um significante" (DERRIDA, 2007, p. 473). Desta forma, o próprio autor da carta está fora do jogo: "Portanto, a responsabilidade do autor passa ao segundo plano, comparada àquela de quem a detém" (LACAN apud DERRIDA, 2007, p. 468). A aposta de Lacan no significante como "materialidade singular", a fim de potencializar sua circulação e não sua mensagem, mas seu poder de significante único é lida por Nancy e Labarthe em $O$ título da letra ${ }^{1}$ (1991). Ao discutir dois conceitos chaves em Lacan, letra e suporte material, Nancy e Labarthe afirmam:

[...] de um lado, o Seminário sobre "A carta roubada", onde se sabe que a partir da carta (a missiva) que dá seu título à novela de Poe e que, urge lembrar, está escondida em lugar tão evidente que ninguém a enxerga, Lacan chama de materialidade do significante ao mesmo tempo a aptidão do significante para a localização, sua "relação com o lugar". Mas uma localização que, estranhamente, é sempre uma "ausência em seu lugar". (NANCY; LACOUE-LABARTHE, 1991, p. 36)

Assim, Nancy irá ler em Lacan nem um idealismo (origem), nem um materialismo (sentido), o que seria a dupla recusa de Lacan na sua defesa da materialidade do signo. Desta

\footnotetext{
${ }^{1}$ Este livro de Nancy e Labarthe - que segundo os autores não é um livro, mas o fruto de um estudo que precisou de um livro pela extensão que adquiriu - é recomendado não só por Derrida, como "fundamental e indispensável", mas também pelo próprio Lacan. Esta análise de Nancy e Labarthe é focada no seminário "A instância da letra no inconsciente ou a razão desde Freud".
} 
forma, a letra será pensada não como substância, mas matéria e ainda como lugar do inconsciente. O sujeito é sujeitado à letter. Nancy parte do princípio que a lógica do significante lacaniano ainda parte de uma teoria do sujeito. Evidentemente que este sujeito não é um:

sujeito no sentido clássico do termo [...] isto é, de um sujeito capaz de significação ou do querer-dizer (presente aqui sob a forma de "querer ser entendido" [...] A significação parte do jogo dos significantes, e não da vontade ou não-vontade dos sujeitos. (NANCY; LACOUE-LABARTHE, 1993, p.74)

Nancy entenderá então uma lição lacaniana: a letra é o lugar do inconsciente. Temos assim dois elementos, além da fundamental potência do significante letter ser carta e letra para a leitura de uma correspondência:

* Os papéis fixos e estabelecidos de remetente e destinatário estão, ou precisam estar, abalados. É preciso depor o arconte;

* A correspondência não é uma simples troca de mensagens, mas um jogo complexo de tomada de posições ambivalentes.

Ainda Lacan, quinze anos depois do Seminário, em Lituratera, afirmará que não se tratava do conteúdo da carta, mas de como ela cumpriu seu destino nos desvios no caminho: "pois o conto consiste em fazer desaparecer num passe de mágica a mensagem e a carta seguir as peripécias sem ela" (LACAN) ${ }^{2}$. Tomar o Seminário de Lacan como referência para leitura de alguma correspondência como troca de mensagens/informações seria no mínimo um equívoco. Então, interessam mais, sem dúvida, as peripécias da carta do que sua mensagem. Entretanto, Derrida (2007, p. 471) detectará tais peripécias como um movimento circular “ela estará onde ela sempre terá estado, sempre terá devido estar, intangível e indestrutível através do desvio de um trajeto próprio e propriamente circular”. Este desvio é garantido pelo serviço de Dupin e é justamente essa percepção do trajeto circular que possibilitará uma intervenção do leitor voyeur de cartas, que ao assumir o mesmo papel que o investigador amador e poeta Dupin assume na narrativa de Poe, o de entrar no percurso da correspondência, mas, diferentemente do dele, não tratará de recolocá-la no lugar da lei (a Lei que une o Rei e a Rainha), mas de buscar a tarefa impossível de mantê-la fora-da-lei, no sentido de não estar a serviço de um partido, nem do Rei, nem da Rainha, nem do seu elo.

Por mais que um artista/poeta em um caso de correspondência não tivesse intenção de publicar suas cartas, ou que até mesmo rejeitasse tal ideia, requerendo que não fossem

\footnotetext{
${ }^{2}$ Este texto está disponível na internet, conforme indicado nas "Referências". Seguem o mesmo caso todos os textos citados mas sem data e/ou paginação na referência no corpo do texto.
} 
publicadas, mantendo-as em segredo, seguindo a esteira do ministro D., também poeta, seria traído no seu desejo de esconder a carta. O ministro D. não podia simplesmente eliminar a carta, senão perderia o poder de sua posse, era preciso mantê-la em segredo, mas intacta. Entretanto, neste jogo da verdade, Lacan (1998, p.24) relembra a alethés de Heidegger: "é ao se ocultar que ela mais verdadeiramente se oferece a eles." A verdade, ou a mensagem, fatalmente virá à tona. Ou alguma verdade, que já estava implícita no jogo, como afirmará Derrida em nota:

[...] O Seminário se contradiz quando, com algumas linhas de intervalo, radicaliza a lógica do significante e de seu lugar literal pretendendo neutralizar a "mensagem", e, em seguida, arrazoa ou ancora essa lógica em seu sentido ou sua verdade simbólica: "essa carta permanece como o símbolo de um pacto". (DERRIDA, 2007, p. 537)

Ali, a lógica do significante interrompe o semanticismo ingênuo. (DERRIDA, 2007, p. 467)

Assim como o jogador de cartas, que ora mantém uma carta virada para si, defendendo-a dos olhares alheios, sabe que na próxima rodada esta mesma carta será outra, não lhe pertencendo mais, e ainda terá seu antigo conteúdo desvendado. O mesmo objeto significante tem duas faces que variam de posição e de posse. É desta maneira que acontece um jogo bipolar na correspondência entre poetas/artistas. Da mesma forma que o melhor lugar para se esconder um livro será, paradoxalmente, em uma biblioteca. Fora do seu lugar comum de ordenação, estará escondido apesar de completamente à vista. Porém, certamente um dia será encontrado, ao acaso ou não. Independentemente do desejo do autor e da mensagem emitida, a correspondência de um poeta é, no Jogo de cartas, uma "mensagem na garrafa" lançada ao mar, como afirma Armando Freitas Filho (apud CESAR, 1999, p.9) em apresentação à edição da Correspondência Incompleta de Ana Cristina Cesar.

A questão ética da leitura da correspondência de outrem não é somente a violação do arquivo, mas como e em que medida o leitor de arquivo se implica naquilo que a correspondência diz. O amigo que conta a verdade também é julgado somente pelo ato de manifestá-la, tornar o privado público: "isso tudo não quer dizer que, por mais que o segredo da carta seja indefensável, a denúncia desse segredo seja de algum modo honrosa” (LACAN, 1998, p. 32). Silviano Santiago, no seu texto de título emblemático "Suas cartas, nossas cartas", - prefácio da correspondência entre Mario de Andrade e Drummond, prefácio que adquirira valor já à parte, tendo sido publicado em coleção de ensaios - nos recorda:

Ao invadir a intimidade da letra epistolar, estamos sendo, antes de tudo, transgressores. Contemplado por convenção jurídica, o limite entre o privado e o público, no tocante à socialidade proporcionada pelo serviço dos correios \& 
telégrafos, é lei clara na cultura do Ocidente. A correspondência é inviolável. (SANTIAGO, 2006, p.61)

Mas Silviano também tratará de nos absolver elencando alguns motivos que nos permitem a transgressão, principalmente o fator da "altitude alcançada pelo artista e pela obra" e ainda por "uma nova teoria literária" (SANTIAGO, 2006, p. 63). Ou seja, uma ética do arquivo preocupada com o problema da correspondência não se limitará à questão "ler ou não ler?", mas sim em como ler. A história de uma carta, narrada por Poe, analisada por Lacan/Derrida é a história do deslocamento de um significante. Mas este deslocamento não seria justamente a história de toda correspondência publicada? A saída, desejada ou não, de um âmbito privado/individual para o público/em massa. Em um documentário intitulado "Encontro com Lacan", um de seus analisandos relata que o analista fechava a porta de seu consultório quando iria atender, mas também a deixava aberta algumas vezes. Este fato permitia uma espécie de alívio para os pacientes que aguardavam na fila do lado de fora, ao ouvirem e perceberem, por exemplo, os temores de um complexo de Édipo serem de ordem coletiva, não individual. Público, não privado. Certamente temos um problema da ética da psicanálise, que também tem sua lei clara em relação à privacidade do analisando, mas que Lacan desafiava com o gesto de "esquecer" a porta aberta.

Liliana Heer, em "La correspondência: uma voz en el camino", colocará a correspondência na ordem do excesso, ou seja, aquilo que transborda a obra do escritor:

La correspondencia es uno de los grande géneros literarios que nos permite acceder al registro del excesso, el secreto y lo obsceno (fuera da escena). Obviamente, excede los circuitos del destinatário. [...] contato de primera instancia de carácter privado que después de la muerte cobraron estado público. (HEER, 1995)

Entretanto, é interessante notar como, de alguma forma, o artista já está munido da consciência da contingência da morte, ou seja, da contingência de que sua correspondência privada será, em algum momento de sua história, pública. Então, apesar da "lei clara no Ocidente", não há carta ingênua nesse processo. O artista que se encontra em uma cena de correspondência prevê, de uma forma ou de outra, que seu destinatário é in-definido. Esta contingência pode ser usada inclusive de forma estratégica pelo escritor. Não somente via a quase nobre "carta aberta", mas é também a partir do processo de escolha do destinatário que se pode encontrar um elo justamente com o meio público:

Oscar Wilde es uno de los escritores que mejor expresó la voluntad de publicar su correspondencia, gesto que sostuvo a todo riesgo, incluso el de ir a prisión. En De Profundis, epístola de manifiesto sentido político, confiesa su homosexualidad y 
describe la relación amorosa con Lord Alfred Douglas. Idéntica lógica utiliza el Marqués de Sade, su correspondencia es al mismo tiempo un medio y un estilo de confesión pública. (HEER, 1995)

Desta forma, parece-me que a correspondência entre escritores funciona, a despeito dos modos de leitura específicos solicitados, como um poema com dedicatória. O poeta escreve um poema munido de intenção que o direcione para algum outro poeta/amigo, entretanto, este poema certamente chegará até nós, independentemente do seu sentido prévio indicado na dedicatória. Além ainda da consciência da carta/letra/poema tornar-se pública, há propriamente o desejo que ela se manifeste para além do seu destinatário pré-estabelecido. Em A escrita de si, Michel Foucault resgatará a tradição epistolar via Sêneca, no qual Foucault percebe como a máxima moral de Séneca: "devemos pautar a nossa vida como se toda a gente a olhasse" (SÉNECA apud FOUCAULT, 1992, p.151). Nesse sentido, a escrita de si, que abrange até a correspondência, - apesar de a princípio ser uma escrita para o outro pois, segundo Sêneca: “escrevemos lendo, dizemos ouvindo", é também um exercício de pudor. Há então um trabalho no exercício da correspondência que a permite inclusive ser elevada ao nível, até mesmo superior, da ficção de um escritor. Ainda Heer:

En algunos autores, la correspondencia supera en calidade literaria a la obra. Simone de Beauvoir afirmó que las cartas de Sartre son lo mejor de su narrativa y Emile Cioran, en su ensayo Mania epistolar, admite que le resulta imposible reeler a Flaubert, pero que experimenta un poder vivificador ante sus cartas. (HEER, 1995)

Neste mesmo ensaio citado, Emile Cioran afirmará também o contrário: "No se pode decirse lo mismo - excepción trágica - de las de Proust, exasperantes a más no poder, insoportablemente obsequisas". Cioran, apesar de sem rodeios considerar que a epistolografia é um gênero, parte de uma perspectiva da negatividade; da não-obra, do não-trabalho: "Habiendo tenido la suerte, como he dicho, de ser toda mi vida un desocupado, he escrito un número considerable de cartas." Aqui, novamente, a carta é encarada como excesso no sentido de abundância mesmo, é a partir da inoperância - "Al indolente, la correspondencia le da la ilusion de la actividade" - de ser um desocupado que lhe permitiu um volume vasto de cartas. Há outro elemento importante no paradoxo - número considerável de nada - de Cioran: "durante muchos años mantuve una correspondencia sin objeto con toda clase de transtornados." (CIORAN, 2000). Em cena, a loucura e sua ausência de obra, a correspondência "sem objeto" e a condição para existência da própria amizade. No ensaio "O amigo", Giorgio Agamben nos relata a experiência epistolar que estabeleceu com Nancy, afim de discutirem o tema amizade via correspondência, eis o resultado: 
A chegada da carta de Jean-Luc significou o fim do projeto. Mas é certo que a nossa amizade, que nos nossos propósitos deveria nos ter aberto um acesso privilegiado ao problema - foi para nós, ao contrário, um obstáculo e, de algum modo, resultou ao menos provisoriamente obscurecida. (AGAMBEN, 2009, p.80)

A estranheza do desfecho do episódio, talvez um caso emblemático de correspondência que teve um fim definido, o retorno da primeira carta é a última carta, recebe explicação já no fim do texto. A amizade, para Agamben $(2009$, p.80) não possui um objeto compartilhado, ela é relação em si: "os amigos não condividem algo". O que para Cioran possibilitou uma experiência de amizade via correspondência, pois sin objeto, significou a impossibilidade da correspondência para Agamben e Nancy, pois criou um objeto em meio a amizade já existente.

O episódio de Agamben e Nancy é curioso, no sentido que é um circuito que teve fim, porque tradicionalmente um evento de correspondência tende ao fragmentário e ao disperso, para um jogo infinito. Segundo Josefina Ludmer:

La oscilación entre texto proprio y texto (discurso, voz) del otro que produce el proprio, la posibilidad de reversiones constantes en el campo de los pronombres personales, la necesidad de absorber el relato del otro para poder replicar y de suponer siempre otra carta (anterior o futura) para poder escribir, hacen de la forma epistolar un depósito de las propriedades de la escritura en campo de la propriedad: no se sabe de quién es la carta, si de aquel que la escribió, dijo yo y citó al otro, o de quién la recibe e la detenta, de quien lee yo. (LUDMER, 1975, p. 3)

Ludmer nos apresenta esta cena da escrita da correspondência como um jogo bipolar, de uma escritura em que a autoria é construída a quatro mãos, e não somente pelo remetente ou destinatário, mas pelo remetente $e$ destinatário na mesma carta/letra, configurando aquilo que Nancy (1991, p. 80) chamará como uma lógica do desejo, que articula o significante em cena não a partir do je (eu), mas com o jeu (jogo). Assim, Ludmer nos oferece o cerne da questão para pensar o problema do arquivo em um caso de correspondência: radicalização do problema do autor e do arquivo. Derrida em Mal de arquivo apresenta o que seria a figura primordial de autoridade do arquivo: o arconte. Os primeiros guardiões do arquivo, que não somente os guardavam como também "tinham o poder [hermenêutico] de interpretar os arquivos". (DERRIDA, 2001, p.13). Juridicamente e editorialmente, o arquivo de uma correspondência fica em mãos do destinatário, aquele que recebia as cartas, mas a autoria e seus direitos ficam ainda reservados aos herdeiros. A figura do arconte destinatário acaba detendo um poder político de representação e interpretação do sentido da correspondência. Mas se, como vimos, toda carta é estruturalmente roubada e voadora, quem é o arconte? É neste sentido que, independentemente do personagem, o arconte precisa ser deposto, posto em xeque, a fim de garantir que a correspondência 
mantenha aquela potência do seu desvio de percurso. É o leitor voyeur de uma correspondência que garante que a carta/letra seja justamente sujeito, não objeto, ao promover um desvio de percurso. Este movimento faz parte do que Derrida designará como violência arquival: "todo arquivo é ao mesmo tempo instituidor e conservador. Revolucionário e tradicional.” (DERRIDA, 2001, p.17)

Diante desta ambivalência do arquivo, de um lugar indefinido, entramos consequentemente em outra questão que é a da obra de um autor. Logo no início do conto de Poe, o narrador nos diz o seguinte: "in company with my friend Auguste Dupin, in his little back library, or book closet, [...]" (POE, 2008, p.121), trecho que Julio Cortazar traduzira como "en su pequena biblioteca o gabinete de estudos", e que Borges curiosamente traduzirá como "en su biblioteca", somente. Borges parece propor então uma indiferença em relação ao tamanho ou a posição dessa biblioteca, mas o que parece interessar no original de Poe são justamente os significantes little e back, que apontam para um lugar não-central, o que parece ser exatamente o lugar da letter, carta/letra, de um artista/poeta. A leitura de René Major em Lacan com Derrida é fundamental para essa questão do sem-lugar da carta: "Nenhum dos dois vê [o narrador e o leitor] - seja na primeira entrevista, ou talvez desde a primeira - que Dupin já está com a carta e que o chefe de polícia intuiu isso.” (MAJOR, 2002, p.116 - grifo meu) Ou seja, Major oferece uma leitura do conto de Poe que indica que a carta nunca esteve em outro lugar, do momento da narrativa, senão nas mãos de Dupin, em sua posse em seu "gabinete de estudos" ou sua "pequena biblioteca". Ao pensar o lugar do livro e da obra, Foucault nos indaga:

\begin{abstract}
A constituição de uma obra completa ou de um opus supõe um certo número de escolhas difíceis de serem justificadas ou mesmo formuladas: será que basta juntar aos textos publicados pelo autor os que ele planejava editar e que só permaneceram inacabados pelo fato de sua morte? Será preciso incluir, também, tudo que é rascunho, primeiro projeto, correções e rasuras dos livros? Será preciso reunir esboços abandonados? E que importância dar às cartas, às notas, [...] (FOUCAULT, 2008, p.26)
\end{abstract}

A única definição acerca do lugar da carta, dos episódios de correspondência, de um autor já consagrado é que seu lugar não é um ponto pacífico. No caso da edição das "obras completas" do próprio Edgar Alan Poe , organizada pela Wordsworth Edition, na coleção "Wordsworth Library Edition", estão reunidas a prosa e a poesia de Poe. A coleção não apresenta o termo "complete", mas somente "collected works" (2009), já no caso de

\footnotetext{
${ }^{3}$ Ambas as traduções estão disponíveis em: < http://www.cartas.org.ar/De\%20ficcion/fic-poe-aaa.html >. Acesso em 16/10/2013.
} 
Shakespeare, a edição da mesma coleção assume a completude da obra: "the complete works" (2007). Ou seja, a edição de Poe, a princípio, não tem a pretensão de apresentar a obra completa, por outro lado intitula a coleção como "library", o que permitiria a ideia de completude, a ideia da própria biblioteca do autor. A despeito da diferença entre "collected" e "complete", ambas reúnem prosa e poesia dos autores, mas nada de alguma correspondência. Novamente a carta está na sua ausência, não conquistando o atributo de "work", como no caso Cioran, para adquirir a legitimidade de pertencer a uma obra completa.

Em "Sobre o procedimiento epistolar", Juan José Saer indagará a estabilidade da correspondência como gênero, ideia que Heer e Cioran, por exemplo, não questionam, mas afirmam. Saer (1997) colocará a correspondência como uma forma de "pretexto literario para encubrir formalmente um monólogo", seja de ordem moral, religiosa, filosófica, estética, científica, etc. Entretanto, esta possibilidade não lhe garantirá o conceito de gênero, mas de um procedimento. "El epistolar no es un género. Es más bien un procedimiento”. Afirmará ainda Saer:

El procedimiento epistolar tiene, por lo tanto, estructuras precisas y un margen de oscilación perfectamente limitado. Su elección no puede ser arbitraria. Quienes lo conciben como un género, pretenderán que sus posibilidades de utilización son infinitas. No es así. En cierto modo, también la poesía y la novela son procedimientos. Pero eso queda para otra vez. (SAER, 1995)

Apesar de afastar a ideia da correspondência como um gênero, colocando-a como procedimento, Saer, por outro lado, de maneira ambivalente, a aproximará da literatura, pois afirma também que a poesia e o romance seriam procedimentos. Evidencia assim Saer que, a questão central da crítica, ficção e criação do século XX, a do procedimento, é também uma questão para a própria correspondência. Ou seja, a condição da carta, gênero ou procedimento, é uma possível relação de aproximação com e entre a literatura. A letter é letra, possibilidade de literatura. Mas, seu lugar não é de fácil encontro. Roberto Ferro ao ler o romance Filho de homem de Augusto Roa Bastos encontrará uma série de indícios que contribuirão para construir uma literatura a partir do nada, diante do vazio do passado literário paraguaio, que construirão um texto e um elo possível entre seus personagens:

Os traços, os rastros, as estrias, as manchas, as rachaduras, os coágulos, as cicatrizes, os riscos, os buracos, as crostas, as marcas, as gretas, os resquícios, as entranhas, os interstícios, as fissuras, as rugas, os cotocos, os veios, os orifícios, as frinchas, as ruínas, os coalhos, as trincheiras, as talhaduras, as brechas, os arranhões, as pústulas, as escaras, as roturas, os mapas, os croquis, as cartas, os informes, que talham, lavram, rasgam, arranham, gravam, cortam, raspam, roçam, sulcam, aram, estrujam, queimam, laceram, eriçam, arrastam, incrustam, embrulham, enrugam, demarcam, roem, inscrevem [...] (FERRO, 2010, p.125) 
$\mathrm{O}$ arquivo é vasto, impreciso e a carta é mais um elemento entre uma série de pistas e caminhos. Encontrá-la é uma tarefa nitidamente difícil - apesar da astucia e eficiência que nos vende o detetive Dupin - e mesmo depois de um encontro, a previsão e alcance dos seus efeitos é também de uma série imprecisa, exatamente como a mensagem na garrafa lançada ao mar. A carta/letra tem um e vários destinos.

\section{Referências}

AGAMBEN, Giorgio. O amigo. In: $O$ que é contemporâneo? E outros ensaios. Trad. Vinícius Nicastro Honesko. Argos: Chapecó, 2009. p. 77- 92

FREITAS, Armando Filho; HOLLANDA, Heloisa Buarque (Org.). Correspondência incompleta. Ana C. Rio de Janeiro: Aeroplano, 1999.

CIORAN, Emile. Manía epistolar. In: Ejercicios de admiración y otros textos. Barcelona: Tusquets $\quad$ Editores, 2000. Disponível em: < http://bibliotecaignoria.blogspot.com/2007/03/emile-cioran-mana-epistolar.html $>$. Acesso em: 16 out. 2013.

DERRIDA, Jacques. O cartão-postal: de Sócrates a Freud e além. Trad. Ana Valéria Lessa e Simone Perelson. Rio de Janeiro: Civilização Brasileira, 2007.

Mal de arquivo: uma impressão freudiana. Trad. Cláudia de Moraes Rego. Rio de Janeiro: Relume Dumará, 2001.

FERRO, Roberto. Filho de homem de Augusto Roa Bastos. Uma reescrita do texto ausente. In: Da literatura e dos restos. Trad. Jorge Wolff. Florianópolis: Ed. da UFSC, 2010. p. 121131.

FOUCAULT, Michel. Arqueologia do saber. Trad. Luiz Felipe Baeta Neves. 7. ed. Rio de Janeiro: Forense Universitária, 2008.

A escrita de si. In: O que é um autor?. Lisboa: Passagens, 1992. p. 129-160.

HEER, Liliana. La Correspondencia: Una Voz en el Camino. In: Cartas en la Realidad y la Ficción. Desde la Gente Ediciones, Instituto Movilizador de Fondos Cooperativos C.L. Buenos Aires, $1995 . \quad$ Disponível em: http://www.lilianaheer.com.ar/cartas/cartas_prologo.html >. Acesso em: 16 out. 2013.

LACAN, Jacques. Escritos. Trad. Vera Ribeiro. Rio de Janeiro: Jorge Zahar Ed., 1998.

Lituratera. Trad. Luiz de Souza Dantas Forbes. Disponível em: < http://www.psicanaliselacaniana.com/estudos/documents/LiturateracomlogoIPLA.pdf $>$. Acesso em: 16. out. 2013.

LUDMER, Josefina. Onetti: La novia (carta) robada (a Faulkner). In: Hispamérica. Año 3, n.9, feb, 1975. pp.3-19. Disponível em < http://www.jstor.org/stable/20541269 $>$. Acesso em 16 out. 2013. 
MAJOR, Rene. Lacan com Derrida. Trad. Fernanda Abreu. Rio de Janeiro: Civilização Brasileira, 2002.

NANCY, Jean-Luc; LABARTHE-LACOUE, Philippe. O título da letra: uma leitura de Lacan. Trad. Sérgio Joaquim de Almeida. São Paulo: Escuta, 1991.

POE, Edgar Alan. A carta roubada. In: Histórias extraordinárias. Trad. José Paulo Paes. São Paulo: Companhia das letras, 2008. p.48-68.

. The Purloined Letter. In: The collected Tales and Poems of Edgar Allan Poe. London: Wordsworth Library Collection, 2009. p.121-134.

SHAKESPEARE, William. The complete works of William Shakespeare. London: Wordsworth Library Collection, 2007.

SAER, Juan José. Sobre el procedimento epistolar. In: El concepto de ficción, Buenos Aires, Ariel, 1997. Disponível em: < http://www.cartas.org.ar/lecturas/lec-sae-sob.html >. Acesso $\begin{array}{llll}\text { em } & 16 & \text { out. } & 2013 .\end{array}$ SANTIAGO, Silviano. Suas cartas, nossas cartas. In: Ora (direis) puxar conversa! Ensaios literários. Belo Horizonte: Editora UFMG, 2006.

[Recebido em agosto de 2012 e aceito para publicação em outubro de 2013]

\section{The Letter and the play of the correspondence}

Abstract: The present essays has as it bottom line the short story "The Purloined Letter" by Edgar Alan Poe and the respectives analysis done by Jacques Lacan in "O Seminário A carta roubada" (Escritos, 1998) and by Jacques Derrida in "O carteiro da verdade" (O cartãopostal, 2007), beyond the reading by Nancy and Labarthe in $O$ título da letra and also Rene Major in Lacan com Derrida, with the wager at the potency of the significant letter/lettre that has a double meaning as "carta" and as "letra", with its potency, as letter, as possible literature. The present work concern aswell with another readings, about epistolography, by Josefina Ludmer, Emile Cioran, Juan José Saer, Liliana Heer, Silviano Santiago. The present work approaches aswell the reading by Michel Foucault in "A escrita de si" (O que é um autor?, 1992) arguing that the correspondence as a way of "escrita de si", despite it is destinated, in principle to an other. The present essays has as principle objective to think the proceeding of correspondence between artists/poets as a play of ambivalent positions, and not as how a static share between the remitter and the receiver.

Keywords: Letters. Correspondence. Epistolography. Derrida. Lacan.

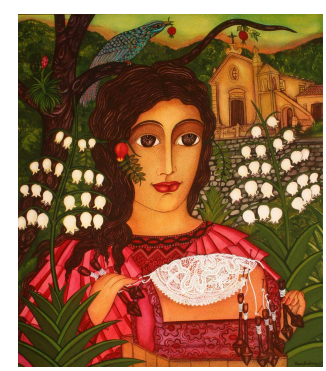

